\title{
Organic Growth Hormone Deficiency
}

National Cancer Institute

\section{Source}

National Cancer Institute. Organic Growth Hormone Deficiency. NCI Thesaurus. Code C120115.

Growth hormone deficiency due to an identifiable biological cause. 